\title{
Associations between socio-demographics, nutrition knowledge, nutrition competencies and attitudes in community-dwelling older adults in Singapore: Findings from the SHIELD study
}

Rebecca Hui Shan Ong ( $\square$ Beckybecks@gmail.com )

Changi General Hospital https://orcid.org/0000-0001-8978-0557

Wai Leng Chow

Ministry of Health Holdings Pte Ltd

Magdalin Cheong

Changi General Hospital

Gladys Huiyun Lim

Changi General Hospital

Weiyi Xie

Abbott Nutrition

Geraldine Baggs

Abbott Nutrition

Dieu Thi Thu Huynh

Abbott Nutrition

Hong Choon Oh

Changi General Hospital

Choon How How

Singhealth

Ngiap-Chuan Tan

SingHealth Polyclinics

Siew Ling Tey

Abbott Nutrition

Samuel Teong Huang Chew

Changi General Hospital

\section{Research}

Keywords: Nutrition knowledge, nourished, community-dwelling, older adults, cross-sectional study

Posted Date: February 27th, 2020 
DOI: https://doi.org/10.21203/rs.2.24748/v1

License: (우 (i) This work is licensed under a Creative Commons Attribution 4.0 International License. Read Full License 


\section{Abstract}

Objectives Nutrition literacy refers to an individual's knowledge, motivation and competencies to access, process, and understand nutrition information needed to make appropriate nutrition-related decisions. It is known to influence dietary habits of older adults. This cross-sectional study was designed to: (1) understand the nutrition knowledge, competencies and attitudes of community-dwelling older adults in Singapore (2) examine the differences between their nutrition knowledge, and socio-demographic factors, competencies and attitudes, and (3) identify factors associated with better nutrition knowledge in community-dwelling older adults in Singapore.

Methods 400 (183 males and 217 females) nourished community-dwelling older adults aged 65 years and above took part in this study. Malnutrition Universal Screening Tool (MUST) was used to determine individuals who were at low risk of undernutrition. Nutrition knowledge, competencies, attitudes and sources of nutrition information were measured using a locally developed scale. Nutrition knowledge scores were summed to form the Nutrition Knowledge Index (NKI). Associations between NKI, competencies, attitudes and socio-demographic variables were examined using Chi-square and Fisher's Exact tests. Factors associated with NKI were determined using a stepwise regression model with resampling based methods for model averaging.

Results Bivariate analyses found significant differences in NKI scores for gender, monthly household earnings, type of housing, the self-reported ability to seek and understand nutrition information and having access to help from family/friends. Females had higher NKI scores compared to males $(p<0.001)$. Compared to females, more males left food decisions to others $(p<0.001)$, and fewer males reported consuming home cooked food $(p=0.016)$. Differences in educational level were found for competencies like the self-reported ability to seek $(p<0.001)$ and verify nutrition information $(p<0.001)$. Stepwise regression analysis showed that being female, Chinese, self-reported ability to understand nutrition information and having access to help from family/friends were associated with higher NKI scores.

Conclusions Our study revealed that nutrition knowledge of older males in Singapore was lower than females and more left food decisions to others. Hence, nutrition education programs could be targeted at both the older male and their caregivers.

\section{Background}

Singapore is a multi-ethnic urban city state with the second-fastest aging population in Asia(1). The proportion of older adults in Singapore aged 65 years and above has increased from $8.8 \%$ in 2008 to $14.4 \%$ in 2019 (2). In Singapore, about 30\% of community-dwelling older adults aged 55 years and above were at risk of poor nutritional status (3). For older adults, it is well recognized that poor nutrition is associated with adverse clinical and functional outcomes like physical frailty, higher mortality, longer inpatient stays and increased intensive care need (4-7).

Nutrition literacy is a subset of health literacy (8). It is defined as the extent to which individuals are able to attain, assess, and understand basic nutrition information required to make appropriate nutrition-related 
decisions $(8,9)$. Key elements of nutrition literacy include nutrition knowledge, competencies and attitudes (10).

Although associations between nutrition literacy and health related outcomes have not been established in existing literature, studies have shown that elements of nutrition literacy can influence dietary habits. Wardle and colleagues reported that nutrition knowledge plays a pivotal role in healthy dietary habits, and partially mediates socio-demographic variations in dietary intakes (11). A recent meta-analysis reported a significant, albeit weak positive association between nutrition knowledge and healthy eating (12). It is also well recognized that healthy eating in older adults is multi-faceted and shaped by both individual and collective factors (13-17). An individual's competency in obtaining, understanding nutrition information, and knowing how to access nutrition health services have an impact on the nutrition knowledge of the individual. Studies have reported that the lack of aforementioned skills may contribute to poor nutrition health $(10,18)$. Nutrition attitudes is centered on the perceptions and beliefs influencing food choices (13, 14), mediating the link between nutrition knowledge and dietary habits (19). A systematic review reported associations between better nutrition knowledge, positive dietary attitudes and healthy dietary habits (20). This is supported by more recent research noting similar associations within Asian and Western older adults $(14,21)$.

Socio-demographic factors such as higher educational qualification, were associated with better nutrition knowledge (22), and positive nutrition attitudes in older adults $(14,23)$. Gender differences were also reported to be associated with nutrition knowledge, with some studies reporting older adult females having higher nutrition knowledge scores than males $(24,25)$, and other studies noting the opposite $(14,22)$.

There are several published instruments in existing literature which measure levels of nutrition knowledge, competencies and attitudes of participants. However, these instruments vary widely and were mostly either developed for Caucasians or validated in a predominantly Caucasian population (26). This is important as there is a cultural aspect to nutrition literacy and behaviour $(10,27,28)$. Given the cultural diversity of the Asian population, it is important to develop instruments that are tailored to each culture and group. Aihara and Minai had previously developed a nutrition literacy instrument for older Japanese people (24), however, items were based on dietary guidelines specific to Japan. The nutrition knowledge, attitudes and behavior scale in Taiwan's Elderly Nutrition and Health Survey consisted of questions on Chinese traditional beliefs on food ("heaty" or "cooling") and food-texture (14), which might not be applicable to older adults of different ethnicities. There is no instrument that is currently relevant for Singapore's multi-ethnic population; hence, the nutrition literacy questionnaire (NLQ) was developed for the purpose of this study.

To design nutrition interventions for older adults, it is crucial to understand their current levels of nutrition knowledge, attitudes and competencies gaps and to understand factors associated with nutrition knowledge. However, there is a dearth of local studies that examine the nutrition knowledge of older adults. Hence, the aims of this study are to: (1) understand the nutrition knowledge, competencies and attitudes of community-dwelling older adults in Singapore (2) examine the associations between nutrition knowledge, and socio-demographic factors, competencies (e.g. ability to obtain and understand information on nutrition) and attitudes, and (3) identify factors associated with better nutrition knowledge. 


\section{Methods}

\section{Participants}

Data was collected as part of the Strengthening Health In ELDerly through nutrition (SHIELD) study. In this cross-sectional study, we analysed a subgroup of older adults $(N=400)$ recruited between September 2017 and January 2018 from four study sites located in the eastern part of Singapore, namely Changi General Hospital (CGH), Bedok Polyclinic, Marine Parade Polyclinic, and Tampines Polyclinic. Participants were eligible for this study if they met the following criteria: aged 65 years and above, Malnutrition Universal Screening Tool (MUST) score was 0 , a community dweller, community ambulant with or without aid, able to communicate and follow instructions, and with or without any stable chronic disease(s), which is defined as a controlled disease state (29). Participants were ineligible for the study if they were diagnosed with any of the following: type 1 or type 2 diabetes mellitus, dementia, active infectious disease (tuberculosis, Hepatitis B or C, HIV infection), severe gastrointestinal disorders (celiac disease, short bowel syndrome, pancreatic insufficiency, or cystic fibrosis), end stage organ diseases, pre-terminal diseases, acute myocardial infarction within the last 30 days, or any active malignancy within the last five years. This study was approved by SingHealth Centralised Institutional Review Board (ref no. 2017/2273) and was registered at clinicaltrials.gov (ref. NCT03240952).

\section{Measures}

Nutritional status of participants was assessed by trained study personnel using the Malnutrition Universal Screening Tool (MUST) (30). The MUST consists of three main scoring components, namely body mass index (BMI), recent unplanned weight loss, and effects of acute disease. Low risk of undernutrition was defined as MUST score $=0(31,32)$. BMI was calculated to the nearest $0.1 \mathrm{~kg} / \mathrm{m}^{2}$. Height was measured to the nearest $0.01 \mathrm{~m}$, and weight was measured to the nearest $0.1 \mathrm{~kg}$ using a weight and height machine (Avamech B1000) calibrated according to the manufacturer's specifications. Information on medical history, socio-demographics (i.e., age, sex, ethnicity, education, marital status, living arrangements, residential type, and financial situation), and lifestyle (i.e., smoking, alcohol consumption) of the participants were also collected via self-administered questionnaires. Age was categorized into $<75$ or $\geq$ 75 years. Education was categorized into primary, secondary, pre-university, and university and above. Information on physical health was obtained through the Charlson Comorbidity Index (CCl) (33) and Modified Barthel Index (MBI) instruments (34).

\section{Nutrition Knowledge, Competencies and Attitudes}

The NLQ was developed using evidence from published literature, nutritional knowledge materials published by the local health promotion agency (35) and expert inputs. The instrument was piloted and tested among some of Dietitians and found to be acceptable and able to capture the nutrition literacy level of older adults. The instrument was then translated and back translated into Chinese and Malay, the two other most commonly used languages in Singapore. 
The NLQ consisted of three main components namely nutrition knowledge, competencies, and attitudes. Sources of nutrition information and factors influencing food choices were also collected and analysed separately. Firstly, nutrition knowledge of participants was assessed based on their knowledge of local nutritional recommendations outlined in The Recipe For Healthy Ageing: Nutrition Guide (35). There were 7 multiple choice questions, each question had three possible answers to choose from, and there was only one correct answer. Questions covered food groups and recommended portion sizes. A score of 1 was assigned for a correct response and 0 for otherwise. Scores were summed to form the Nutrition Knowledge Index (NKI). Total scores ranged from 0 to 7, with higher scores indicating better knowledge level. Secondly, nutrition competencies of participants were assessed using 9 binary questions. For example, "Do you know where to go to find information about nutrition? (Yes/No)". Thirdly, nutrition attitudes of participants were measured using 4 statements (e.g. "It is not important to eat nutritious meals at my age") related to their dietary habits and the participants were asked to rate each of these statements on a four-point Likert scale ( 4 = Strongly Agree, 3 = Agree, 2 = Disagree, 1 = Strongly Disagree). Participants could choose more than one option(s) for sources of nutrition information and factors influencing their food choices.

\section{Statistical analysis}

All analyses were performed using SAS version 9.4 (SAS Institute, Cary, NC, USA), and significance level was set at 0.05 . The responses on the Likert scale were also re-categorized. "Strongly agree" and "Agree" were categorised together as "Agree", while "Strongly disagree" and "Disagree" were categorised together as "Disagree". The option "Refused to answer/don't know" for monthly household earnings (SGD) was excluded from analyses. Chi-square and where appropriate, Fisher's exact tests were used for tests of associations between nutrition knowledge, competencies, attitudes and socio-demographic factors. Stepwise multiple linear regression modeling was used to examine the factors associated with the nutrition knowledge index. Bivariate analyses results were taken into consideration together with literature in this area for variables selection. Model inputs consisted of 20 potential variables (gender, ethnicity, education level, marital status, living arrangements, caregiving arrangements, residences type, NLQ questions on competencies and attitudes). Resampling based methods for model averaging were used to mitigate for known limitations of stepwise selection including selection bias in parameter estimates and reliance on a single best model (36).

\section{Results}

\section{Participant Characteristics}

The demographic profile of the study sample is shown in Table 1. Of the 400 participants, $217(54.2 \%)$ were females. Majority were married (74.2\%), of Chinese ethnicity $(83.0 \%)$, and had education levels of secondary level and above (84.5\%) with a mean age of 71.2 years. Majority were independent according to MBI (93.0\%) and a Charlson Comorbidity score of 0 (98.0\%).

\section{Table 1. Characteristics of study participants}




\begin{tabular}{|c|c|c|}
\hline & $n$ & $\%$ \\
\hline \multicolumn{3}{|l|}{ Gender } \\
\hline Male & 183 & 45.8 \\
\hline Females & 217 & 54.3 \\
\hline \multicolumn{3}{|l|}{ Age categories, $n(\%)$} \\
\hline$<75$ years & 301 & 75.2 \\
\hline$\geq 75$ years & 99 & 24.8 \\
\hline \multicolumn{3}{|l|}{ Ethnicity, $n(\%)$} \\
\hline Chinese & 332 & 83.0 \\
\hline Others & 68 & 17.0 \\
\hline \multicolumn{3}{|l|}{ Marital status, $n(\%)$} \\
\hline Married & 297 & 74.2 \\
\hline Single & 103 & 25.8 \\
\hline \multicolumn{3}{|l|}{ Highest level of education, $n(\%)$} \\
\hline Primary & 62 & 15.5 \\
\hline Secondary & 186 & 46.5 \\
\hline Pre-university & 100 & 25.0 \\
\hline University and above & 52 & 13.0 \\
\hline \multicolumn{3}{|l|}{ Smoking status, $n(\%)$} \\
\hline Non-smoker & 333 & 83.3 \\
\hline Daily/Occasional smoker & 10 & 2.5 \\
\hline Past smoker & 57 & 14.3 \\
\hline \multicolumn{3}{|c|}{ Alcohol consumption in the last 12 months, $n(\%)$} \\
\hline No alcohol & 287 & 71.8 \\
\hline$<$ Once a month & 69 & 17.3 \\
\hline$\geq$ Once a month & 44 & 11.0 \\
\hline \multicolumn{3}{|l|}{ Modified Barthel Index, $n(\%)$} \\
\hline Moderate Dependence (60-79) & 7 & 1.8 \\
\hline Slight dependence (80-99) & 21 & 5.3 \\
\hline Independent (100) & 372 & 93.0 \\
\hline \multicolumn{3}{|l|}{ Charlson Comorbidity Score, $n(\%)$} \\
\hline 0 & 392 & 98.0 \\
\hline 1 & 6 & 1.5 \\
\hline 2 & 1 & 0.3 \\
\hline 3 & 1 & 0.3 \\
\hline \multicolumn{3}{|l|}{ Household eamings/month (SGD) } \\
\hline$<2,000$ & 166 & 41.5 \\
\hline $2,000-3,999$ & 66 & 16.5 \\
\hline $4,000-5,999$ & 32 & 8.0 \\
\hline 6,000 and above & 38 & 9.5 \\
\hline Refused to answer/don't know & 98 & 24.6 \\
\hline \multicolumn{3}{|l|}{ Housing Type } \\
\hline 1-3 room public flats & 74 & 18.5 \\
\hline 4-5 room public flats & 186 & 46.5 \\
\hline Private properties and others & 140 & 35.0 \\
\hline
\end{tabular}

\section{Socio-Demographic factors and Nutrition Knowledge, Competencies and Attitudes}

Gender differences between nutrition knowledge, competencies, and attitudes are shown in Table 2. Compared to males, more females correctly identified portion sizes for wholegrains ( $58.1 \%$ vs. $38.3 \%$; $p<$ 
$0.001)$ and proteins $(p=0.02)$. More females made their own food decisions $(p<0.001)$ and consumed home cooked food compared to males. More males agreed that they would eat simpler meals if alone/with spouse $(55.2 \%$ vs. $43.8 \% ; p=0.02)$. In addition, most participants agreed with the importance of consuming nutritious meals (91.1\%) and would cease consumption of their favourite foods if they discovered them to be unhealthy (82.8\%). Majority preferred eating home-cooked meals (94.5\%), although $196(49 \%)$ agreed that they were more likely to eat simpler meals if alone/with spouse.

\section{[Insert Table 2 here]}

Table 3 shows nutrition knowledge index by socio-demographic factors, competencies and attitudes. A higher nutrition index was noted for females, those who reported and average household earnings of less than SGD\$2,000, individuals who lived in private properties. For nutrition related competencies, a higher NKI score was noted for individuals who self-reported an ability to seek nutrition information $(p=0.011)$, understood nutrition information ( $p=0.008$ ), did not leave food decisions to others $(p=0.012)$, had access to help from family or friends $(p=0.009)$, and did not consume simpler meals when alone/ or only with spouse $(p=0.016)$.

\section{[Insert Table 3 Here]}

Table 4 shows the associations of sociodemographic factors with competencies and attitudes. Compared to those with primary level education or below, more individuals with higher educational qualification reported having ability to seek $(p<0.001)$ and verify nutrition information $(p<0.001)$. Compared to currently married individuals, those who were single were less likely to report leaving food decisions to others $(p=0.002)$ Compared to those who lived alone, those who were living with others were more likely to report leaving food decisions to others $(p=0.004)$. In terms of caregiving arrangements, for older adults who reported self-caregiving, majority (81.0\%) made their own food decisions and was able to access healthcare services (94.0\%). However, they reported lower rates of consuming home-cooked food compared to those who were cared for by family or others $(p=0.011)$.

\section{[Insert Table 4 here]}


Most participants reported nutritional value influenced their food choices (78.8\%), and this was followed by taste (59.8\%) and health conditions (53.5\%) (Figure 1).

The results of the stepwise regression are shown in Table 5, it was observed that being female $(p<0.001)$, of Chinese ethnicity $(p=0.026)$, self-reported ability to understand nutrition information $(p=0.035)$, and having access to help from family/friends $(p=0.051)$ was associated with higher NKI.

Table 5. Factors associated with nutrition knowledge index

Unstandardized Coefficients

\begin{tabular}{|c|c|c|c|}
\hline $\begin{array}{l}\text { Model } \\
\text { Gender }\end{array}$ & $\beta$ & Std. Error & P value \\
\hline Males & 0 & & \\
\hline Females & 0.4213 & 0.09924 & $<0.001$ \\
\hline \multicolumn{4}{|l|}{ Ethnicity } \\
\hline Non-Chinese & 0 & & \\
\hline Chinese & 0.4213 & 0.09924 & 0.026 \\
\hline \multicolumn{4}{|c|}{ Able to understand nutrition information } \\
\hline Yes & 0 & & \\
\hline No & -0.4469 & 0.2115 & 0.035 \\
\hline \multicolumn{4}{|c|}{ Has access to help from family/friends } \\
\hline Yes & 0 & & \\
\hline No & -0.3531 & 0.1802 & 0.051 \\
\hline
\end{tabular}

\section{Sources of Nutritional Information}

Figure 2 shows the most commonly cited sources of nutrition information. Among the study participants, the most commonly cited source(s) was the television $(40.0 \%)$, internet $(40.0 \%)$, followed by traditional print media such as newspapers (39.3\%), books/magazines (32.3\%), and word of mouth like through friends $(20.3 \%)$ and family (14.3\%). Compared to males, females were significantly more likely to turn to television ( $45.2 \%$ vs. $33.9 \%)$, radio $(19.8 \%$ vs. $8.7 \%)$ and friends $(24.4 \%$ vs. $15.3 \%)$ for nutrition information.

\section{Discussion}

To the best of our knowledge, this is the first study of its kind to examine the nutrition knowledge, competencies and attitudes amongst relatively healthy Singapore older adults, and the results might be useful for guiding nutrition strategies in the population. 
Though some studies have been conducted on nutrition literacy among Asian older adults $(14,24)$, their instruments were specially designed for their respective local populations. Thus, it is difficult to compare the nutrition literacy levels of our participants with that of other studies. We found nutrition knowledge and other aspects of nutrition competencies and attitudes (such as responsibility of food decisions, consumption of home-cooked meals, and consumption of simpler meals when alone/with spouse) differ significantly between the genders. Education might have a role in the ability of older adults to seek and verify nutrition information while caregiving arrangements might have an influence on the responsibility of food decisions and consumption of home-cooked meals among the study population. Moreover, higher nutrition knowledge index is found to be associated with being female, of Chinese ethnicity, self-reported ability to understand nutritional information, and having access to help from family/friends.

Males were found to have a lower nutrition knowledge index. They were also more likely to leave food decisions to others, less likely to consume home-cooked meals, and more likely to consume simpler meals when alone/with spouse. These suggest that more support might need to be offered to older male adults to improve their nutrition knowledge so that they are able to make appropriate food choices, especially when they are dining out. On the other hand, it remains unclear why males prefer to leave food decisions to others and this could potentially be explored as a future research study.

Education is known to contribute to an individual's ability to better understand, and remember different information (37), and educated adults were suggested to be more motivated and interested in nutritional health $(13,23)$. This is in line with our bivariate analyses which showed that older adults with higher education levels had a higher proportion with the self-reported ability to seek and verify nutrition related information compared to those with primary education levels. The current study did not find an association between age and nutrition knowledge index. Previous studies on older adults noted that nutrition knowledge decreased as age increased $(13,14,38)$. However, Parmenter et al. found a non-linear trend between different age cohorts and nutrition knowledge scores, and suggests the influence of upbringing and lifestyle on nutrition knowledge (39). Lin and Lee reported that while dietary habits of the older Taiwanese were strongly influenced by Chinese traditional food-related beliefs (i.e. heaty foods, cold foods, etc.), education had an effect on these beliefs. Higher educated individuals were less likely to report their food choices being influenced by these traditional beliefs. The cohort in the present study is highly educated, $13.0 \%$ had education levels of University and above compared to $5.8 \%$ of Singapore's general population aged 65 years and above. The lack of association between age and nutrition knowledge could have been due to the higher education levels, which might have reduced the influence of traditional cultural food beliefs.

Older adults who are cared for by family or others reported a higher likelihood of consuming home cooked meals compared to those who are self-reliant for care. Moreover, the former group is more likely to leave food decisions to the discretion of others compared to those who are self-reliant for care. These suggests that employed caregivers or family members living together with older adults should be included in nutritional education programs targeted at the older adults as they play an important role in ensuring the nutrition health of their older dependents. 
Findings on the factors associated with higher nutrition knowledge index from this study highlighted that older male adults need more assistance to improve their nutrition knowledge compared to the female counterparts. Our results which showed that older female adults had higher nutrition knowledge than males are similar to what was reported by Aihara and Minai in the Asian older adults population and by Shatenstein et al in the Western older adults population $(24,25)$. This could be due to females taking on more domestic responsibilities, including meal preparation and food choices (40), and are thus more likely to be familiar with nutrition related information. It is also important to note the self-reported ability to understand nutrition information and having access to family and friends for help are contributing factors to the learning and encoding of nutrition knowledge, and therefore yielding a higher nutrition knowledge index. Nutritional educational programs which offer small incremental blocks of information content was suggested to booster learning and maximize retention of nutrition among adults (41). Such an approach may be useful in designing of the nutrition strategies to mitigate age-related declines in comprehension amongst older learners. The role that social networks play in the nutritional well-being of older adults has been well established in literature (42-44). In this study, about 14-20\% of older adults reported obtaining their nutrition information through their social networks. This highlights the importance of social and community aspects when designing nutrition strategies. Though majority of the participants in this study reported that nutritional value as a crucial factor influencing their food choices, almost half of the study cohort were more likely to eat simpler meals (i.e. biscuits and milo/pickled vegetables with rice) when dining alone or with spouse. This again highlights the importance of social networks in influencing the nutrition behavior of older adults where they eat more and eat better in social environments with family or friends (45).

It was evident from this study that ethnicity was associated with NKI with older Chinese adults scoring better NKI than others. This finding is similar to that of a previous study conducted in Malaysia, the study's sample consisted of Malays (46.0\%), Chinese (32.0\%), Indians (6.0\%), and other minority groups (16.0\%) aged 60 to 96 years old (22). The authors found that those of Chinese ethnicity had the highest proportion with good nutrition knowledge compared to the other groups. This highlights that development of nutrition programs may have to be customized according to cultural practices and with sensitivity.

\section{Sources of Nutrition Information}

Understanding the sources for nutrition information among the older population is crucial in developing nutrition educational outreach methods. Studies on Asian older adults have found television to be one of the most commonly cited resource of nutritional information, which range from $49.7-79.8 \%$, followed by printed materials, social networks and health professionals $(14,24)$. Internet was not included as an option in these studies and hence it is difficult to establish the proportion of older adults who considered the internet as a source. Similarly, our study reported television (40.0\%) as one of the most common sources of information, followed by printed materials like newspapers (39.3\%). Our study's reported proportion of internet as a source of information was higher compared to recent studies done in Midwest US on older adults aged 60 years and above (0.4\%) (46) and in Australia older adults aged 65 years and above (19.0\%) 
(47). This could be due to the higher education levels and socioeconomic status seen in our participants compared to Singapore's general population aged 65 years and above.

\section{Limitations}

There are four limitations in this study. Firstly, the participants in this study were relatively healthy and educated with normal nutritional status (MUST =0). Caution should be taken when generalizing these results to other older population groups. Secondly, the cross-sectional design means that causal relationship between nutrition knowledge, competencies, attitudes, and factors associated with them could not be established. Future studies are needed to understand and confirm the associations in this study. Thirdly, the psychometrics properties of the NLQ have yet to be established, future studies are planned to validate the questionnaire. Lastly, associations between nutrition knowledge, competencies and attitudes and dietary habits could not be determined due to a lack of dietary intake information. Future studies could capture dietary intake to examine the associations.

\section{Conclusions}

Gender, ethnicity, the self-reported ability to understand nutrition information, and having access to help from family and friends are significant factors associated with nutrition knowledge of the older adult population of normal nutrition status in Singapore. To align with the national strategy of improving population health, nutrition interventional programs on the older adults may have to be targeted on older males and their caregivers. Moreover, it is important that the nutrition interventional programs are designed with culturally appropriate messaging to maintain racial harmony in multi-cultural landscape of Singapore. Television and the internet could be considered as potential media for educational program outreach. Overall, the findings of this study offer relevant insights on how to devise effective public health educational interventions to improve nutritional knowledge in older adults.

\section{Abbreviations}

BMI

Body Mass Index

$\mathrm{CCl}$

Charlson Comorbidity Index

$\mathrm{MBI}$

Modified Barthel Index

MUST

Malnutrition Universal Screening Tool

NKI

Nutrition Knowledge Index

NLQ

Nutrition Literacy Questionnaire 


\section{Declarations}

\section{Ethics declarations}

\section{Ethics approval and consent to participate}

The research project was approved by the SingHealth Centralised Institutional Review Board (CIRB Ref: 2017/2273). The purpose of the study was fully explained to all participants and written informed consent was obtained from all participants.

\section{Consent for publication}

Not applicable.

\section{Availability of data and materials}

The datasets from this current study are available from the corresponding author on reasonable request.

\section{Competing interests}

WX, GB, DTTH and SLT are employees of Abbott Nutrition. STHC reports receiving honoraria for speaking engagement and travel grant from Abbott. All other authors have declared that no competing interests.

\section{Funding}

The SHIELD study is supported by the Singapore Economic Development Board (EDB), Changi General Hospital and Abbott Nutrition.

\section{Authors' contributions}

STHC, MC, SLT, DTTH, RHSO, WLC, NCT, CHH were responsible for the design and protocol of the study. RHSO did the literature review and drafted the manuscript. GHL \& RHSO contributed to the acquisition of data. WX and GB performed the statistical analysis, and RHSO, HCO, WLC, STHC, SLT, DTTH, MC, CHH, NCT, WX, GB, and GHL were involved in the interpretation of data and critically reviewing the manuscript. All authors read and approved the final manuscript.

\section{Acknowledgments}

We would like to extend our thanks to all the co-investigators, and study teams of Abbott Nutrition, Changi General Hospital and SingHealth Polyclinics for their assistance and contribution to the study.

\section{Authors' information}

\section{Affiliations}

Department of Geriatric Medicine, Changi General Hospital, Singapore 
Samuel Teong Huang Chew

Department of Dietetics and Food Services, Changi General Hospital, Singapore

Gladys Huiyun Lim \& Magdalin Cheong

Health Services Research, Changi General Hospital, Singapore

Rebecca Hui Shan Ong, Wai Leng Chow \& Hong Choon Oh

Care and Health Integration, Changi General Hospital, Singapore

Choon How How

Abbott Nutrition Research and Development, Columbus, United States of America

Weiyi Xie \& Geraldine Baggs

Abbott Nutrition Research and Development, Asia-Pacific Center, Singapore

Siew Ling Tey \& Dieu Thi Thu Huynh

SingHealth Polyclinics, Singapore

Ngiap-Chuan Tan

\section{References}

1. United Nations. World Population Ageing 2017. Highlights. New York, NY, USA2017.

2. Singapore Department of Statistics. Population trends 2019. 2019.

3. Wei K, Nyunt MSZ, Gao Q, Wee SL, Ng T-P. Frailty and malnutrition: related and distinct syndrome prevalence and association among community-dwelling older adults: Singapore longitudinal ageing studies. J Am Med Dir Assoc. 2017;18(12):1019 - 28.

4. Kim J, Lee Y, Won CW, Lee KE, Chon D. Nutritional status and frailty in community-dwelling older Korean adults: the Korean frailty and aging cohort study. J Nutr Health Aging. 2018;22(7):774 - 8.

5. Gaudreau P, Morais JA, Shatenstein B, Gray-Donald K, Khalil A, Dionne I, et al. Nutrition as a determinant of successful aging: description of the Quebec longitudinal study NuAge and results from cross-sectional pilot studies. Rejuvenation Res. 2007;10(3):377 - 86.

6. Kagansky N, Berner Y, Koren-Morag N, Perelman L, Knobler H, Levy S. Poor nutritional habits are predictors of poor outcome in very old hospitalized patients. Am J Clin Nutr. 2005;82(4):784 - 91.

7. Neumann SA, Miller MD, Daniels L, Crotty M. Nutritional status and clinical outcomes of older patients in rehabilitation. J Hum Nutr Diet. 2005;18(2):129 - 36.

8. Sørensen K, Broucke SVd, Fullam J, Doyle G, Pelikan J, Slonska Z, et al. Health literacy and public health: a systematic review and integration of definitions and models. BMC Public Health. 
2012;12(80).

9. Silk KJ, Sherry J, Winn B, Keesecker N, Horodynski MA, Sayir A. Increasing nutrition literacy: testing the effectiveness of print, web site, and game modalities. J Nutr Educ Behav. 2008;40(1):3-10.

10. Velardo S. The nuances of health literacy, nutrition literacy, and food literacy. J Nutr Educ Behav. 2015;47(4):385 - 9.

11. Wardle J, Parmenter K, Waller J. Nutrition knowledge and food intake. Appetite. 2000;34(3):269 - 75.

12. Spronk I, Kullen C, Burdon C, O'Connor H. Relationship between nutrition knowledge and dietary intake. Br J Nutr. 2014;111(10):1-14.

13. Jeruszka-Bielak M, Kollajtis-Dolowy A, Santoro A, Ostan R, Berendsen AAM, Jennings A, et al. Are nutrition-related knowledge and attitudes reflected in lifestyle and health among elderly people? a study across five european countries. Front Physiol. 2018;9:1 - 13.

14. Lin W, Lee Y-W. Nutrition knowledge, attitudes, and dietary restriction behavior of the Taiwanese elderly. Asia Pac J Clin Nutr. 2005;14(3):221 - 9.

15. Payette H, Shatenstein B. Determinants of healthy eating in community-dwelling elderly people. Can $\mathrm{J}$ Public Health. 2005;96(Suppl 3):S27 - S31.

16. Dean M, Raats MM, Grunert KG, Lumbers $M$, Team TFiLL. Factors influencing eating a varied diet in old age. Public Health Nutr. 2009;12(12):2421 - 7.

17. Worsley A. Nutrition knowledge and food consumption: can nutrition knowledge change food behaviour? Asia Pac J Clin Nutr. 2002;11(3):S579 - S85.

18. Koo YX, Kang ML, Auyong A, Liau GZ, Hoe J, Long M, et al. Malnutrition in older adults on financial assistance in an urban asian country: a mixed methods study. Public Health Nutr. 2013;17(12):2834 43.

19. Grotkowski M, Sims L. Nutritional knowledge, attitudes, and dietary practices of the elderly. J Am Diet Assoc. 1978;72(5):499 - 506.

20. Axelson ML, Federline TL, Brinberg D. A meta-analysis of food- and nutrition-related research. J Nutr Educ Behav. 1985;17(2):51 - 4.

21. Herne S. Research on food choice and nutritional status in elderly people: a review. Br Food J. 1995;97(9):12 - 29.

22. Karim NA, Safii NS, Yusof SM, Noor NM, Ahmad Z, Siong Te. Nutrition knowledge among Malaysian elderly. Jurnal Sains Kesihatan Malaysia. 2008;6(2):43 - 54.

23. Li C-P. Gender differences in nutrition knowledge, attitude, and practice among elderly people. IJMESS. 2017;6(S1):199 - 211.

24. Aihara Y, Minai J. Barriers and catalysts of nutrition literacy among elderly japanese people. Health Promot Int. 2011;26(4):421 - 31.

25. Shatenstein B, Gauvin L, Keller H, Richard L, Gaudreau P, Giroux F, et al. Baseline determinants of global diet quality in older men and women from the NuAge cohort. J Nutr Health Aging. 2013;17(5):419 - 25.

26. Yuen EYN, Thomson M, Gardiner H. Measuring nutrition and food literacy in adults: a systematic review and appraisal of existing measurement tools. Health Lit Res Pract. 2018;2(3):134 - 60. 
27. Garine ID. The Socio-Cultural Aspects Of Nutrition. Ecol Food Nutr. 1972;1(2):143 - 63.

28. Coe RM, Miller DK. Sociologic Factors that Influence Nutritional Status in the Elderly. In: HJ A, JM P, RM C, editors. Nutritional Intervention in the Aging Process: Springer, New York, NY; 1984. p. 3 - 12.

29. BYL NN, Clever LH. Stable Chronic Disease: A Behavioral Model. J Am Geriatr Soc. 1977;25(9):408 - 14.

30. Elia M. Screening for malnutrition: a multidisciplinary responsibility. Development and use of the 'Malnutrition Universal Screening Tool' ('MUST') for adults. MAG, a Standing Committee of BAPEN (ISBN 189946770 X). 2003.

31. Baek M-H, Heo Y-R. Evaluation of the efficacy of nutritional screening tools to predict malnutrition in the elderly at a geriatric care hospital. Nutr Res Pract. 2015;9(6):637 - 43.

32. Raslan M, Gonzalez MC, Dias MCG, Nascimento M, Castro M, Marques Pc, et al. Comparison of nutritional risk screening tools for predicting clinical outcomes in hospitalized patients. Nutrition. 2010;26(7-8):721 - 6.

33. Charlson ME, Pompei P, Ales KL, MacKenzie CR. A new Method of classifying Prognostic Comorbidity in Longitudinal Studies: Development and Validation. J Chronic Dis. 1987;40(5):373 - 83.

34. Collin C, Wade D, Davies S, Horne V. The Barthel ADL Index: a reliability study. Int Disabil Stud. 1988;10(2):61-3.

35. The recipe for healthy ageing: nutrition guide. Health Promotion Board. Singapore: Health Promotion Board; 2016.

36. Henderson DA, Denison DR. Stepwise regression in social and psychological research. Psychol Rep. 1989;64(1):251 - 7 .

37. Turrell G, Kavanagh AM. Socio-economic pathways to diet: modelling the association between socioeconomic position and food purchasing behaviour. Public Health Nutr. 2007;9(3):375 - 83.

38. Fischer CA, Crockett SJ, Heller KE, Skauge LH. Nutrition knowledge, attitudes, and practices of older and younger elderly in rural areas. J Am Diet Assoc. 1991;91(11):1398 - 401.

39. Parmenter K, Waller J, Wardle J. Demographic variation in nutrition knowledge in England. Health Educ Res. 2000;5:163-74.

40. Sydner YM, Fjellström C, Lumbers M, Sidenvall B, Raats M. Food habits and foodwork. Food Cult Soc. 2015;10(3):367-87.

41. Boulton-Lewis GM. Education and learning for the elderly: why, how, what. Educ Gerontol. 2010;36(3):213-28.

42. Mclntosh WA SP, Picou JS. Social support, stressful events, strain, dietary intake, and the Elderly. Med Care. 1989;27(2):140 - 53.

43. Locher JL RC, Roth DL, Baker PS, Bodner EV, Allman RM. Social isolation, support, and capital and nutritional risk in an older sample: ethnic and gender differences. Soc Sci Med. 2005;60(4):747 - 61.

44. Romero-Ortuno R, Casey A, Cunningham C, Squires S, Prendergast D, Kenny R, et al. Psychosocial and functional correlates of nutrition among community-dwelling older adults in Ireland. J Nutr Health Aging. 2011;15(7):527 - 31. 
45. Vesnaver E, Keller HH. Social influences and eating behavior in later life: a review. J Nutr Gerontol Geriatr. 2011;30(1):2-23.

46. Heuberger RA, Ivanitskaya L. Preferred sources of nutrition information: contrasts between younger and older adults. J Intergener Relatsh. 2011;9(2):176 - 90.

47. D.L. Craven GPL, F.E. Pelly, E. Isenring. Community-living older adults' perceptions of body weight, signs of malnutrition and sources of information: a descriptive analysis of survey data. $J$ Nutr Health Aging. 2018;22(3):393 - 9.

\section{Tables}

Table 2. Nutrition knowledge, Competencies and Attitudes by gender 


\section{Nutrition Knowledge}

Food type - wholegrains, $\mathrm{n}(\%)$

\begin{tabular}{|c|c|c|c|c|}
\hline Incorrect & $41(10.2)$ & $22(12.0)$ & $19(8.8)$ & 0.283 \\
\hline Correct & $359(89.8)$ & $161(88.0)$ & $198(91.2)$ & \\
\hline \multicolumn{5}{|c|}{ Food type - fruits/vegetables, n (\%) } \\
\hline Incorrect & $4(1.0)$ & $3(1.6)$ & $1(0.5)$ & 0.336 \\
\hline Correct & $396(99.0)$ & $180(98.4)$ & $216(99.5)$ & \\
\hline \multicolumn{5}{|c|}{ Food type - meat, n (\%) } \\
\hline Incorrect & $3(0.7)$ & $1(0.5)$ & $2(0.9)$ & 1.000 \\
\hline Correct & $397(99.3)$ & $182(99.5)$ & $215(99.1)$ & \\
\hline \multicolumn{5}{|l|}{ Drink type, $\mathrm{n}(\%)$} \\
\hline Incorrect & $5(1.2)$ & $4(2.2)$ & $1(0.5)$ & 0.183 \\
\hline Correct & $395(98.8)$ & $179(97.8)$ & $216(99.5)$ & \\
\hline \multicolumn{5}{|c|}{ Portion - wholegrains, $\mathrm{n}(\%)$} \\
\hline Incorrect & $204(51.0)$ & $113(61.7)$ & $91(41.9)$ & $<0.001$ \\
\hline Correct & $196(49.0)$ & $70(38.3)$ & $126(58.1)$ & \\
\hline \multicolumn{5}{|c|}{ Portion - fruits/vegetables, n (\%) } \\
\hline Incorrect & $167(41.7)$ & $86(47.0)$ & $81(37.3)$ & 0.051 \\
\hline Correct & $233(58.3)$ & $97(53.0)$ & $136(62.7)$ & \\
\hline \multicolumn{5}{|c|}{ Portion - protein, n (\%) } \\
\hline Incorrect & $130(32.5)$ & $70(38.3)$ & $60(27.6)$ & 0.024 \\
\hline Correct & $270(67.5)$ & $113(61.7)$ & $157(72.4)$ & \\
\hline
\end{tabular}

\section{Nutrition Competencies}

Aware of where to seek nutrition information

\begin{tabular}{|c|c|c|c|c|c|}
\hline a. & Yes & $337(84.3)$ & $149(81.4)$ & $188(86.6)$ & 0.154 \\
\hline $\mathrm{b}$. & No & $63(15.7)$ & $34(18.6)$ & $29(13.4)$ & \\
\hline \multicolumn{6}{|c|}{ Able to understand nutrition information } \\
\hline a. & Yes & $376(94.0)$ & $172(94.0)$ & $204(94.0)$ & 0.993 \\
\hline $\mathrm{b}$. & No & $24(6.0)$ & $11(6.0)$ & $13(6.0)$ & \\
\hline \multicolumn{6}{|c|}{ Able to verify nutrition information } \\
\hline a. & Yes & $196(49.0)$ & $89(48.6)$ & $107(49.3)$ & 0.953 \\
\hline b. & No & $204(51.0)$ & $94(51.4)$ & $110(50.7)$ & \\
\hline \multicolumn{6}{|c|}{ Leaves food decision to others } \\
\hline a. & Yes & $101(25.3)$ & $78(42.6)$ & $23(10.6)$ & $<0.001$ \\
\hline b. & No & $299(74.7)$ & $105(57.4)$ & $194(89.4)$ & \\
\hline \multicolumn{6}{|c|}{ Consumption of home cooked meals } \\
\hline a. & Yes & $361(90.3)$ & $158(86.3)$ & $203(93.5)$ & 0.016 \\
\hline b. & No & $39(9.7)$ & $25(13.7)$ & $14(6.5)$ & \\
\hline \multicolumn{6}{|c|}{ Has access to help from family/friends } \\
\hline a. & Yes & $366(91.5)$ & $166(90.7)$ & $200(92.2)$ & 0.603 \\
\hline b. & No & $34(8.5)$ & $17(9.3)$ & $17(7.8)$ & \\
\hline \multicolumn{6}{|c|}{ Able to access health services } \\
\hline a. & Yes & $395(98.8)$ & $180(98.4)$ & $215(99.1)$ & 0.664 \\
\hline b. & No & $5(1.2)$ & $3(1.6)$ & $2(0.9)$ & \\
\hline \multicolumn{6}{|c|}{ Comfortable sharing dietary information with healthcare professionals } \\
\hline a. & Yes & $391(97.8)$ & $180(98.4)$ & $211(97.2)$ & 0.517 \\
\hline
\end{tabular}




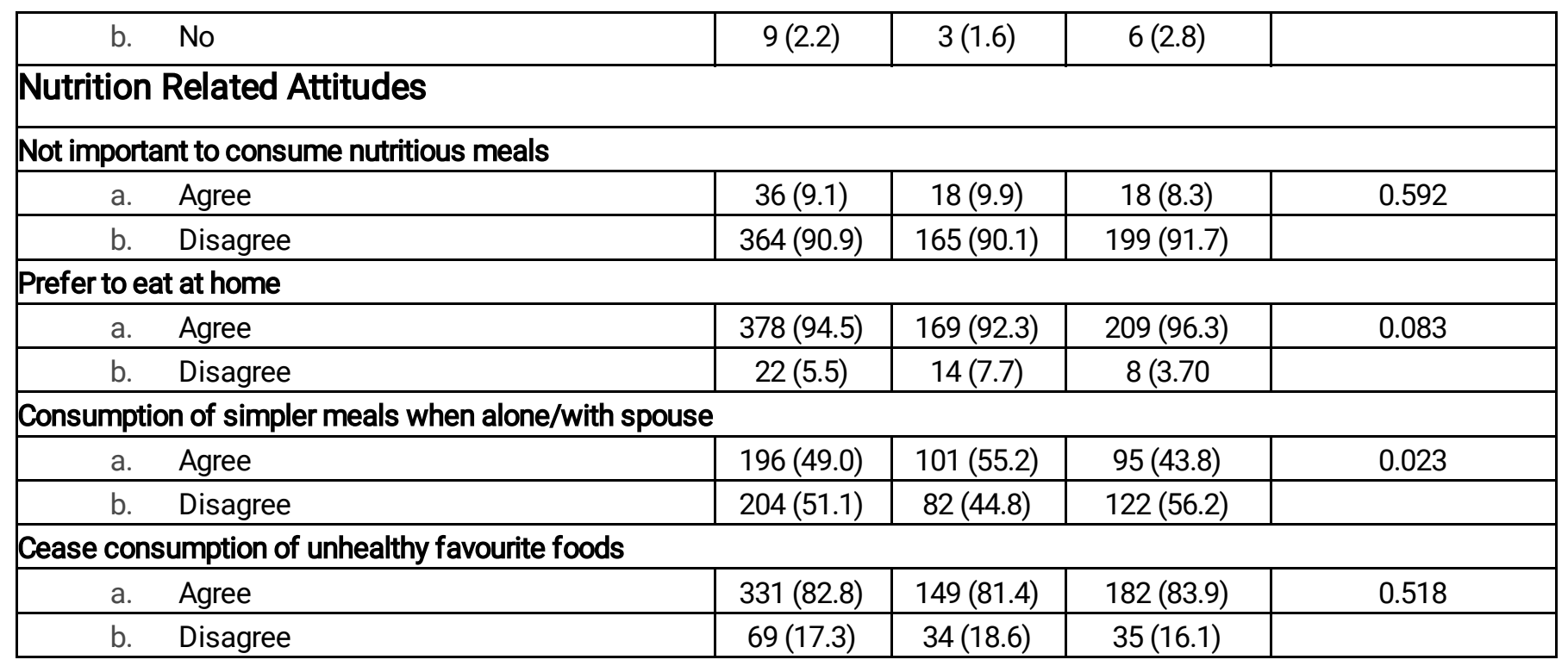

Table 3. Associations between nutrition knowledge, socio-demographics, competencies, and attitudes 


\begin{tabular}{|c|c|c|c|}
\hline & $n(\%)$ & Nutrition Knowledge Index (mean, SE) P & $P$-value \\
\hline \multicolumn{4}{|l|}{ Gender } \\
\hline Male & $183(45.8)$ & $5.37(0.07)$ & $<0.001$ \\
\hline \begin{tabular}{cc|} 
b. Female \\
\end{tabular} & $217(54.3)$ & $5.82(0.07)$ & \\
\hline \multicolumn{4}{|l|}{ Marital Status } \\
\hline a. $\quad$ Married & $297(74.3)$ & $5.56(0.06)$ & 0.079 \\
\hline Single & $103(25.7)$ & $5.77(0.10)$ & \\
\hline \multicolumn{4}{|l|}{ Household eamings/month (SGD) } \\
\hline a. $\quad<2,000$ & $166(41.5)$ & $5.76(0.08)$ & \\
\hline $2,000-3,999$ & $66(16.5)$ & $5.33(0.12)$ & 0.035 \\
\hline c. $4,000-5,999$ & $32(8.0)$ & $5.66(0.18)$ & \\
\hline \begin{tabular}{|c|} 
d. $\quad 6,000$ and above \\
\end{tabular} & $38(9.5)$ & $5.55(0.16)$ & \\
\hline \multicolumn{4}{|l|}{ Housing Type } \\
\hline \begin{tabular}{|ll} 
a. HDB 1-3 room flats \\
\end{tabular} & $74(18.5)$ & $5.73(0.12)$ & \\
\hline b. HDB 4-5 room flats & $186(46.5)$ & $5.47(0.07)$ & 0.026 \\
\hline c. $\quad$ Private properties & $140(35.0)$ & $5.75(0.09)$ & \\
\hline \multicolumn{4}{|l|}{ Education level } \\
\hline $\begin{array}{|ll|}\text { a. } & \text { Primary } \\
\end{array}$ & $62(15.5)$ & $5.66(0.13)$ & \\
\hline b. Secondary & $186(46.5)$ & $5.54(0.07)$ & 0.406 \\
\hline Pre-university & $100(25.0)$ & $5.62(0.10)$ & \\
\hline d. University and above & $52(13.0)$ & $5.81(0.14)$ & \\
\hline \multicolumn{4}{|l|}{ Living arrangements } \\
\hline a. Alone & $35(8.8)$ & $5.54(0.17)$ & \\
\hline With immediate family & $336(84.0)$ & $5.61(0.06)$ & 0.776 \\
\hline \begin{tabular}{|c|l|l} 
c. With helpers/friends/extended family \\
\end{tabular} & $29(7.2)$ & $5.72(0.19)$ & \\
\hline \multicolumn{4}{|l|}{ Caregiving arrangements } \\
\hline $\begin{array}{|ll|}\text { a. } & \text { Alone } \\
\end{array}$ & $54(13.5)$ & $5.56(0.14)$ & \\
\hline b. With immediate family & $208(52.0)$ & $5.52(0.07)$ & 0.072 \\
\hline \begin{tabular}{|c|l} 
c. With helpers/friends/extended family \\
\end{tabular} & $138(34.5)$ & $5.78(0.19)$ & \\
\hline \multicolumn{4}{|l|}{ Aware of where to seek nutrition information } \\
\hline \begin{tabular}{|l|} 
a. $\quad$ Yes \\
\end{tabular} & $337(84.3)$ & $5.67(0.06)$ & 0.011 \\
\hline $\begin{array}{ll}\text { b. No } \\
\end{array}$ & $63(15.7)$ & $5.32(0.13)$ & \\
\hline \multicolumn{4}{|l|}{ Able to understand nutrition information } \\
\hline \begin{tabular}{|l|} 
a. $\quad$ Yes \\
\end{tabular} & $376(94.0)$ & $5.65(0.05)$ & 0.008 \\
\hline $\begin{array}{|ll|}\text { b. No } \\
\end{array}$ & $24(6.0)$ & $5.08(0.21)$ & \\
\hline \multicolumn{4}{|l|}{ Able to verify nutrition information } \\
\hline a. Yes & $196(49.0)$ & $5.64(0.07)$ & 0.764 \\
\hline $\begin{array}{|ll|}\text { b. No } \\
\end{array}$ & $204(51.0)$ & $5.63(0.11)$ & \\
\hline \multicolumn{4}{|l|}{ Leaves food decision to others } \\
\hline $\begin{array}{|ll|}\text { a. } \quad \text { Yes } \\
\end{array}$ & $101(25.3)$ & $5.40(0.10)$ & 0.012 \\
\hline b. No & $299(74.7)$ & $5.69(0.06)$ & \\
\hline \multicolumn{4}{|l|}{ Consumption of home cooked meals } \\
\hline 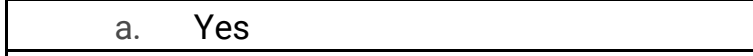 & $361(90.3)$ & $5.62(0.05)$ & 0.622 \\
\hline b. No & $39(9.7)$ & $5.54(0.16)$ & \\
\hline \multicolumn{4}{|l|}{ Has access to help from family/friends } \\
\hline $\begin{array}{|ll|}\text { a. } \quad \text { Yes } \\
\end{array}$ & $366(91.5)$ & $5.66(0.05)$ & 0.009 \\
\hline $\begin{array}{|cc|}\text { b. } \quad \text { No } \\
\end{array}$ & $34(8.5)$ & $5.18(0.17)$ & \\
\hline \multicolumn{4}{|l|}{ Able to access health services } \\
\hline $\begin{array}{ll}\text { a. } & \text { Yes } \\
\end{array}$ & $395(98.8)$ & $5.62(0.05)$ & 0.175 \\
\hline
\end{tabular}




\begin{tabular}{|c|c|c|c|c|}
\hline b & No & $5(1.2)$ & $5.00(0.46)$ & \\
\hline \multicolumn{5}{|c|}{ Comfortable sharing dietary information with healthcare professionals } \\
\hline $\mathrm{a}$ & Yes & $391(97.8)$ & $5.62(0.05)$ & 0.612 \\
\hline$b$ & No & $9(2.2)$ & $5.44(0.34)$ & \\
\hline \multicolumn{5}{|c|}{ Not important to consume nutritious meals } \\
\hline $\begin{aligned} \mathrm{a} \\
\end{aligned}$ & Agree & $36(9.1)$ & $5.31(0.17)$ & 0.056 \\
\hline $\mathrm{b}$ & Disagree & $364(90.9)$ & $5.65(0.05)$ & \\
\hline \multicolumn{5}{|c|}{ Prefer to eat at home } \\
\hline $\mathrm{a}$ & Agree & $378(94.5)$ & $5.63(0.05)$ & 0.160 \\
\hline $\mathrm{b}$ & Disagree & $22(5.5)$ & $5.32(0.22)$ & \\
\hline \multicolumn{5}{|c|}{ Consumption of simpler meals when alone/with spouse } \\
\hline $\mathrm{a}$ & Agree & $196(49.0)$ & $5.49(0.07)$ & 0.016 \\
\hline $\mathrm{b}$ & Disagree & $204(51.1)$ & $5.74(0.07)$ & \\
\hline \multicolumn{5}{|c|}{ Cease consumption of unhealthy favourite foods } \\
\hline $\mathrm{a}$ & Agree & $331(82.8)$ & $5.62(0.06)$ & 0.955 \\
\hline $\mathrm{b}$ & Disagree & $69(17.3)$ & $5.61(0.12)$ & \\
\hline
\end{tabular}

Table 4. Associations between socio-demographic factors, nutrition competencies and attitudes 


\begin{tabular}{|c|c|c|c|c|c|c|c|c|c|c|c|c|c|c|c|c|}
\hline & \multicolumn{5}{|c|}{ Education (\%) } & \multicolumn{3}{|c|}{ Marital Status (\%) } & \multicolumn{4}{|c|}{ Living Arrangements (\%) } & \multicolumn{4}{|c|}{$\begin{array}{c}\text { Caregiving Arrangements } \\
(\%)\end{array}$} \\
\hline & $\begin{array}{l}\text { Primary } \\
(n=62)\end{array}$ & $\begin{array}{c}\text { Secondary } \\
(n=186)\end{array}$ & $\begin{array}{c}\text { Pre- } \\
\text { University } \\
(n=100)\end{array}$ & $\begin{array}{c}\text { University } \\
\text { and } \\
\text { above } \\
(n=52)\end{array}$ & $\begin{array}{l}\mathrm{P}- \\
\text { value }\end{array}$ & $\begin{array}{c}\text { Single } \\
(n= \\
103)\end{array}$ & $\begin{array}{c}\text { Married } \\
(n= \\
297)\end{array}$ & $\begin{array}{l}\mathrm{P} \text { - } \\
\text { value }\end{array}$ & $\begin{array}{c}\text { Alone } \\
(n= \\
35)\end{array}$ & $\mid \begin{array}{c}\text { Family } \\
(n= \\
336)\end{array}$ & $\begin{array}{c}\text { Helpers } \\
\text { friends/ } \\
\text { extended } \\
\text { family } \\
(n=29)\end{array}$ & $\begin{array}{l}\mathrm{P} \text { - } \\
\text { value }\end{array}$ & $\begin{array}{c}\text { Self } \\
(n= \\
54)\end{array}$ & $\begin{array}{c}\text { Family } \\
(n= \\
208)\end{array}$ & $\begin{array}{c}\text { Helpers/ } \\
\text { friend/ } \\
\text { extended } \\
\text { Family } \\
(n=138)\end{array}$ & $\begin{array}{l}\mathrm{P} \text { - } \\
\text { value }\end{array}$ \\
\hline
\end{tabular}

\section{Aware of where}

to seek nutrition

information

\begin{tabular}{cc|c|c|c|c|c|c|c|c|c|c|c|c|c|c|c|}
\hline a. Yes & 63.0 & 85.0 & 88.0 & 98.0 & $<$ & 83.5 & 84.5 & 0.807 & 89.0 & 83.0 & 90.0 & 0.511 & 81.0 & 83.0 & 88.0 & 0.384 \\
\hline b. No & 37.0 & 15.0 & 12.0 & 2.0 & & 16.5 & 15.5 & & 11.0 & 17.0 & 10.0 & & 19.0 & 17.0 & 12.0 & \\
\hline
\end{tabular}

Able to

understand

nutrition

information

\begin{tabular}{cc|c|c|c|c|c|c|c|c|c|c|c|c|c|c|c|c|c|c|c|c|c|}
\hline a. & Yes & 89.0 & 93.0 & 96.0 & 100 & 0.049 & 92.0 & 95.0 & 0.381 & 97.0 & 94.0 & 86.0 & 0.158 & 93.0 & 93.0 & 96.0 & 0.590 \\
\hline b. & No & 11.0 & 7.0 & 4.0 & 0 & & 8.0 & 5.0 & & 3.0 & 6.0 & 14.0 & & 7.0 & 7.0 & 4.0 & \\
\hline
\end{tabular}

Able to verify

nutrition

information

\begin{tabular}{|c|c|c|c|c|c|c|c|c|c|c|c|c|c|c|c|c|c|}
\hline a. & Yes & 10.0 & 49.0 & 63.0 & 67.0 & $\begin{array}{c}< \\
0.001 \\
\end{array}$ & 45.6 & 50.2 & 0.722 & 54.3 & 47.6 & 58.6 & 0.220 & 48.2 & 51.9 & 44.9 & 0.583 \\
\hline b. & No & 54.8 & 18.3 & 15.0 & 11.5 & & 23.3 & 21.9 & & 8.6 & 23.8 & 20.7 & & 18.5 & 20.7 & 26.1 & \\
\hline c. & $\begin{array}{l}\text { Trust } \\
\text { others }\end{array}$ & 35.5 & 32.3 & 22.0 & 21.2 & & 31.1 & 27.9 & & 37.1 & 28.6 & 20.7 & & 33.3 & 27.4 & 29.0 & \\
\hline
\end{tabular}

Leaves food

decision to others

\begin{tabular}{|c|c|c|c|c|c|c|c|c|c|c|c|c|c|c|c|c|c|}
\hline a. & Yes & 19.0 & 26.0 & 29.0 & 23.0 & 0.563 & 14.0 & 29.0 & 0.002 & 3.0 & 28.0 & 21.0 & 0.004 & 19.0 & 33.0 & 17.0 & 0.002 \\
\hline b. & No & 81.0 & 74.0 & 71.0 & 77.0 & & 86.0 & 71.0 & & 97.0 & 72.0 & 79.0 & & 81.0 & 67.0 & 83.0 & \\
\hline
\end{tabular}

Consumption of

home cooked

meals

\begin{tabular}{cc|c|c|c|c|c|c|c|c|c|c|c|c|c|c|c|c|}
\hline a. & Yes & 89.0 & 91.0 & 90.0 & 90.0 & 0.968 & 85.0 & 92.0 & 0.056 & 86.0 & 91.0 & 90.0 & 0.477 & 80.0 & 93.0 & 90.0 & 0.011 \\
\hline b. & No & 11.0 & 9.0 & 10.0 & 10.0 & & 15.0 & 8.0 & & 14.0 & 9.0 & 10.0 & & 20.0 & 7.0 & 10.0 & \\
\hline
\end{tabular}

Has access to

help from

family/friends

\begin{tabular}{|c|c|c|c|c|c|c|c|c|c|c|c|c|c|c|c|c|c|}
\hline a. & Yes & 85.0 & 90.0 & 97.0 & 94.0 & 0.047 & 89.0 & 92.0 & 0.357 & 86.0 & 92.0 & 93.0 & 0.397 & 83.0 & 92.0 & 94.0 & 0.051 \\
\hline b. & No & 15.0 & 10.0 & 3.0 & 6.0 & & 11.0 & 8.0 & & 14.0 & 8.0 & 7.0 & & 17.0 & 8.0 & 6.0 & \\
\hline
\end{tabular}

Able to access

health services

\begin{tabular}{|c|c|c|c|c|c|c|c|c|c|c|c|c|c|c|c|c|c|}
\hline a. & Yes & 98.0 & 99.0 & 98.0 & 100 & 0.789 & 97.0 & 99.0 & 0.110 & 94.0 & 99.0 & 97.0 & 0.031 & 94.0 & 100.0 & 99.0 & 0.031 \\
\hline b. & No & 2.0 & 1.0 & 2.0 & 0.0 & & 3.0 & 1.0 & & 6.0 & 1.0 & 3.0 & & 6.0 & 0.0 & 1.0 & \\
\hline
\end{tabular}

\section{Comfortable}

sharing dietary

information with

healthcare

professionals

\begin{tabular}{|c|c|c|c|c|c|c|c|c|c|c|c|c|c|c|c|c|c|}
\hline a. & Yes & 98.0 & 97.0 & 99.0 & 96.0 & 0.655 & 99.0 & 97.0 & 0.457 & 100 & 97.0 & 100 & 1.000 & 96.0 & 97.0 & 99.0 & 0.236 \\
\hline b. & No & 2.0 & 3.0 & 1.0 & 4.0 & & 1.0 & 3.0 & & 0 & 3.0 & 0 & & 4.0 & 3.0 & 1.0 & \\
\hline \multicolumn{18}{|c|}{$\begin{array}{l}\text { Not important to } \\
\text { consume } \\
\text { nutritious meals }\end{array}$} \\
\hline a. & Agree & 8.0 & 9.0 & 12.0 & 4.0 & 0.414 & 12.0 & 8.0 & 0.275 & 11.0 & 8.0 & 14.0 & 0.392 & 13.0 & 8.0 & 9.0 & 0.473 \\
\hline
\end{tabular}




\begin{tabular}{c|c|c|c|c|c|c|c|c|c|c|c|c|c|c|} 
b. Disagree & 92.0 & 91.0 & 88.0 & 96.0 & & 88.0 & 92.0 & & 89.0 & 92.0 & 86.0 & 87.0 & 92.0 & 91.0 \\
\hline 0. Prefer to eat at
\end{tabular}
home

\begin{tabular}{|c|c|c|c|c|c|c|c|c|c|c|c|c|c|c|c|c|c|}
\hline a. & Agree & 97.0 & 95.0 & 93.0 & 92.0 & 0.618 & 96.0 & 94.0 & 0.404 & 97.0 & 94.0 & 97.0 & 0.903 & 96.0 & 96.0 & 92.0 & 0.286 \\
\hline b. & Disagree & 3.0 & 5.0 & 7.0 & 8.0 & & 4.0 & 6.0 & & 3.0 & 6.0 & 3.0 & & 4.0 & 4.0 & 8.0 & \\
\hline
\end{tabular}

1. Consumption of simpler meals when alone/with spouse

\begin{tabular}{|c|c|c|c|c|c|c|c|c|c|c|c|c|c|c|c|c|c|}
\hline a. & Agree & 45.0 & 49.0 & 51.0 & 50.0 & 0.909 & 43.0 & 51.0 & 0.139 & 34.0 & 51.0 & 41.0 & 0.114 & 37.0 & 52.0 & 49.0 & 0.131 \\
\hline b. & Disagree & 55.0 & 51.0 & 49.0 & 50.0 & & 57.0 & 49.0 & & 66.0 & 49.0 & 59.0 & & 63.0 & 48.0 & 51.0 & \\
\hline
\end{tabular}

2. Cease consumption of unhealthy favourite foods

\begin{tabular}{|c|c|c|c|c|c|c|c|c|c|c|c|c|c|c|c|c|c|}
\hline a. & Agree & 87.0 & 87.0 & 81.0 & 67.0 & 0.009 & 87.0 & 81.0 & 0.149 & 83.0 & 83.0 & 76.0 & 0.593 & 80.0 & 82.0 & 85.0 & 0.667 \\
\hline b. & Disagree & 13.0 & 13.0 & 19.0 & 33.0 & & 13.0 & 19.0 & & 17.0 & 17.0 & 24.0 & & 20.0 & 18.0 & 15.0 & \\
\hline
\end{tabular}

\section{Figures}

Factors influencing food choices

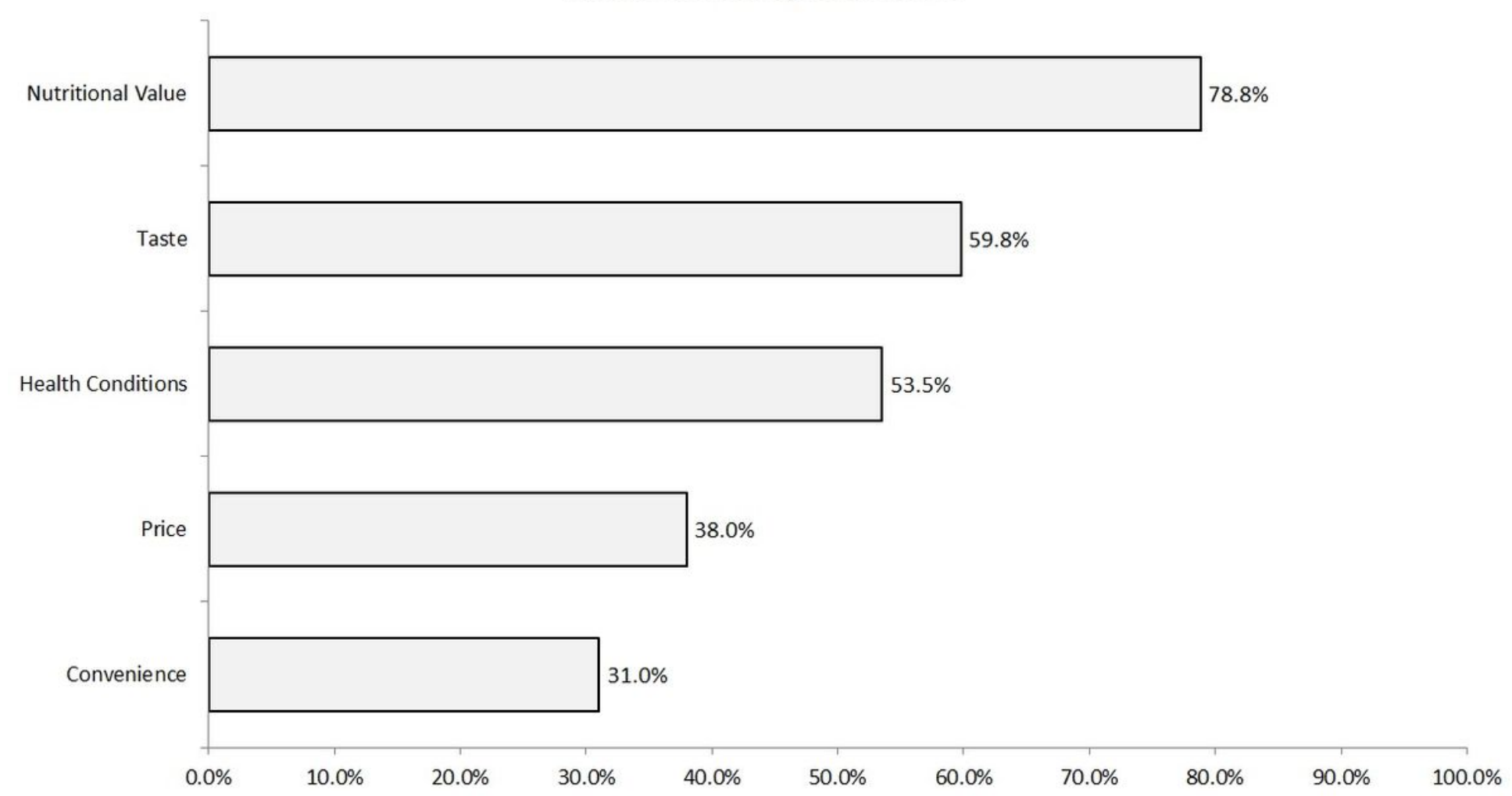

Figure 1

Self-reported factors influencing individual's food choices 


\section{Sources of nutrition information}

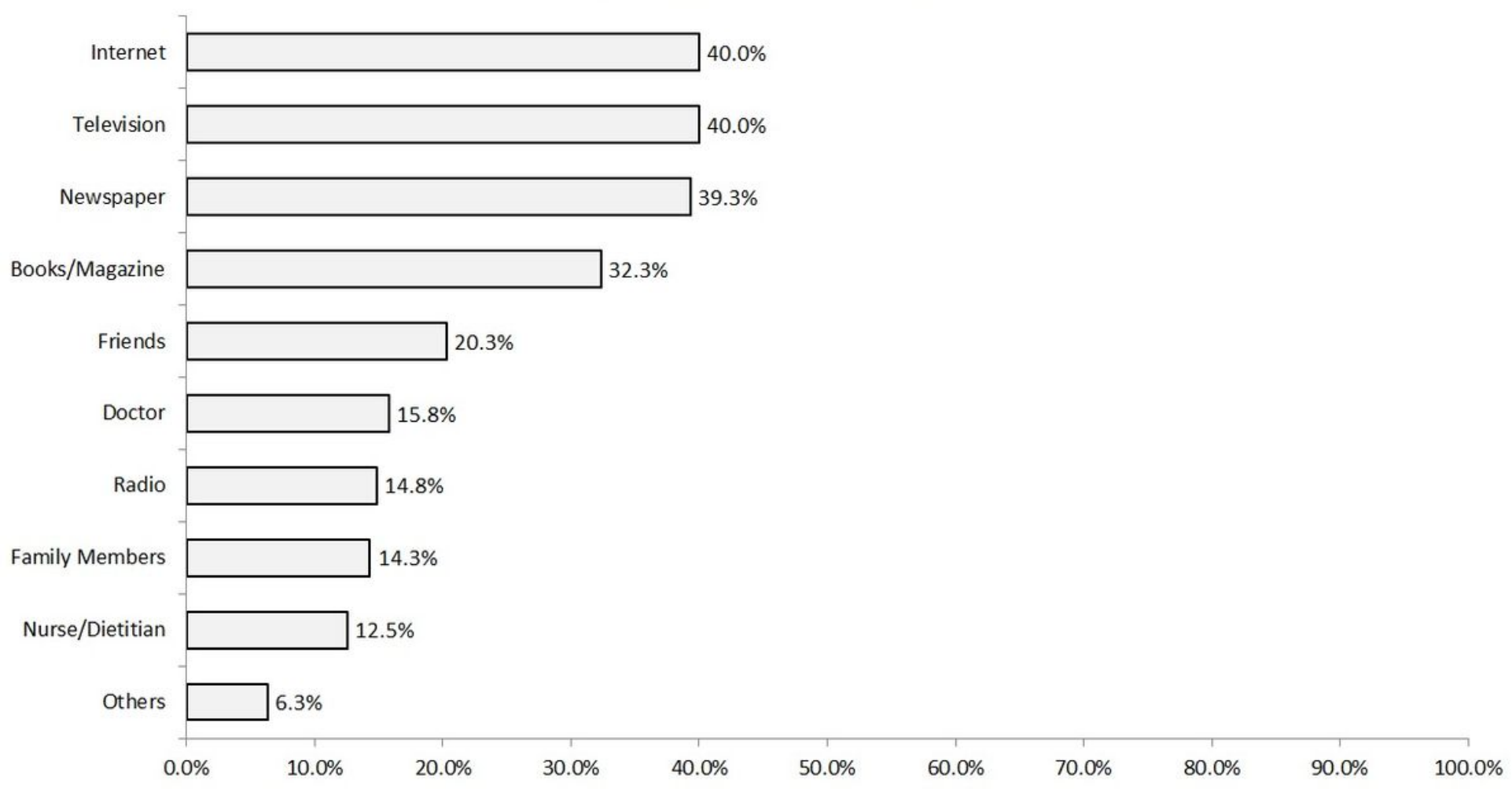

\section{Figure 2}

Sources of Nutrition information 